\title{
Teaching English in a Cross-cultural Context: Challenges and Directions
}

Sharmin Sultana

\begin{abstract}
English as the foremost medium of international communication at present is called upon to mediate a whole range of cultural and cross-cultural concepts, to a greater extent than in the past. Inevitably human capital has taken a slant to fit in with the globalized world, and the notion of 'Teaching English in a Cross-cultural Context' is crucial. Hence, this paper focuses the possibilities and opportunities of multi-cultural education because of the global status of English. Exploring the challenges in teaching English in a cross-cultural context and the way to come out of the deficiency of the learners has been both obscure and controversial since long. What is widely accepted in this regard is English, not being the native language of the learners, triggers some problems. Therefore, the paper highlights core consideration for analyzing the challenges faced by the teachers and learners, and finally, recommends some directions to embrace the challenges.
\end{abstract}

Key words:Teaching English, Cross-cultural context, Native language, Challenges, Directions.

\section{Introduction}

1 language is a part of a culture and a culture is a part of language; the two are intricately interwoven so that one cannot separate the two without losing the significance of either language or culture.

(Brown, cited in Jiang, 1994, p. 147)

English as the foremost medium of international communication at the present time, is called upon to mediate a whole range of cultural and crosscultural concepts, to a greater degree than in the past. No-one involved in teaching English is likely to argue for cross-cultural misunderstanding. Inevitably human capital has taken a slant to fit in with the globalized world, and the notion of 'Teaching English in a Cross-cultural Context' is crucial. Robinson (1985) believes in the importance of developing cultural versatility to help learners meet the demands of an increasingly multicultural world. Nevertheless, there are many challenges related to teaching English in a cross-cultural context and the issue of exploring the challenges and the way to come out of the deficiency of the learners has been a matter of immense concern since long. What is widely accepted in this regard is that English, not being the native language of the learners in a TESOL (Teachers of English to Speakers of Other Language), TEFL (Teaching English as a Foreign Language), EFL (English as a Foreign Language), or ESL (English as a Second Language) context, that is, in a cross-cultural context, triggers some problems. In this paper, there will be four focused areas, like:

- Teaching English in a cross-cultural context,

- The possibilities and opportunities of multicultural education,

- The challenges,

- Some directions to embrace the challenges.

\section{Teaching English in a cross-cultural context}

Hall (1997) explains that culture is something that we do, something that coheres us as a society; 
language, on the other hand, is a way in which we practice culture. But culture itself is never frozen-we consume culture as we produce it and are defined in terms of our use of culture. Pedagogy, likewise, is embedded in and shaped by culture. It is hence important for teachers to be aware of this in their pedagogical practices.

Jiang (1994, p. 27) proposes three different kinds of metaphorical pairs to show the intimate relation between language and culture--flesh/blood, swimming skill/water and vehicle/traffic light.

"Culture is a set of beliefs and values about what is desirable in a community of people and a set of formal or informal practices to support the values" (Javidan \& House: 292). Culture consists of well-established cognitive networks that frame and guide our thoughts, emotions and behaviors without us much noticing the process very much. Culture is also dynamic, with some parts changing and other parts remaining the same depending on a host of variables. Cultures also have room for individual variation, with everyone in a culture not necessarily being the same. Cultures are not written into codes, but culturally prescribed values and norms are always embedded in our social institutions and unwritten rules of discourse and interaction that we learn through the socialization and internalization processes. Furthermore, it has also been suggested that culture exists on a multitude of levels and dimensions in which nationality is only one. (Griffith, Hu, \& Ryans, 2000: 303; Slater, Boone, Price, \& Martinez, 2002:198). Furthermore, people are affected by regional, organizational, family, and work group cultures in addition to national culture, and there are not always clear boundaries where the influence of one culture ends and another begins.

Any teaching and learning context in the world is always a very dynamic and complex environment with a host of variables and forces at work that influence social interaction patterns and resultant levels of performance and productivity. The cross-cultural context has an even higher level of dynamic complexity as there are culture-shaped institutional structures and norms interacting with people of different cultures. It can be exciting, dynamic, creative and productive, but it can also be stressful, confusing, frustrating and nonproductive if teachers, learners and what is being taught, are not integrated properly.

Generally, cross-cultural context refers to including people who have different customs and beliefs. By teaching English in a cross-cultural context, I would like to refer to three dimensions, such as:

Bilingual teachers but students from different cultures,

Native English speaking teacher but students from another culture,

Teacher and students from the same culture but the cultural content of English lessons is from a different culture.

\section{Possibilities and opportunities of multi- cultural education}

Culture has become an increasingly important component of English language teaching in recent time. There are a number of reasons for this related to a view of language that incorporates a wider social and cultural perspective, and to the increasingly multicultural use of English (Will Baker, 2003). The goal of multicultural education is not only to teach learners about other groups or countries. It is also to help them become accustomed to the idea that there are many lifestyles, languages, cultures, and points of view. The purpose of multicultural education is to attach positive feelings to multicultural experiences so that each learner will feel included and valued, and will feel friendly and respectful toward people from other ethnic and cultural groups. Nurturing diversity means making multicultural education a process of action, through which we as adults achieve clarity about our condition in this society and ways to change it (Phillips, 1988). In TEFL, TESOL, ESL, EFL classroom, students are learning English which is not from their own culture. In other words, they are having multicultural education. The prospects of multi-cultural education are:

The global status of English language and the cultural and linguistic qualities of English literature are accepted, appreciated and admired worldwide. Through multicultural literature, learners discover that all cultural groups have 
made significant contributions to civilization. A well-balanced English course includes literature that depicts people with a variety of aspirations, from different sociometric levels, with different occupations, and with a range of human characteristics (Norton, 1985).

Kienle and Loyd (2005: 580) claim globalization is becoming "more prominent in all aspects of civilization. "National differences and antagonism between people are daily more and more vanishing" was a statement in one of history's most influential works written over 150 years ago (Marx \& Engels, 2004/1848: 2). In the current millennium, multicultural and multinational barriers have crumbled down and bridges of communication have gone across lands and seas and English language is the primary medium of communication for world citizens.

In the existing myriad scenes of globalization, the English language classroom can provide the right platform for skills development, and learning opportunities for understanding, empathizing and evaluating the world around. Language teaching is not related to imparting knowledge but is an art as well as a science of developing the skills. According to Wilga M Rivers (1983) foreign language teaching unlike teaching geography or history, is not only a sharing of knowledge but is also a development of the four basic skills of language i.e. listening, speaking, reading and writing. It is an appreciation of a foreign people; it is a readjustment of one's attitude towards the world and towards oneself. In fact, in the path of achieving four skills, a learner has to be exposed to multicultural content so extensively that he attains better understanding; consequently, better attitude towards world around.

English Language Education plays an especially important role in moulding global learners. We need Global Learners who possess the knowledge, skills and attitude needed to critically evaluate and understand the world around them. They need to appreciate cultural differences and rely on this knowledge when participating in this multicultural, interdependent world. Strong support comes from a survey by Timmis (2002), in which the majority of the learners and the teachers of English from a large range of countries expressed a desire to speak English according to the native speaker norms, however the survey also demonstrated a wish to retain the aspects of their own culture, such as accent, especially amongst Asian students (Timmis 2002, 242).

Multicultural education encourages appreciation and understanding of other cultures as well as one's own. Teaching with this perspective promotes the learner's sense of the uniqueness of his own culture as a positive characteristic and enables him to accept the uniqueness of the cultures of others. Students can learn about their class as an example of a common culture. Teachers can emphasize how other classes can be similar and yet different.

\section{Challenges}

Teaching English in a cross cultural context raises a number of challenges. Though we can successfully generalize and predict certain student thought, emotion and behavior patterns, there will always be exceptions to any rules we might formulate. The first and foremost problem faced in teaching English in a cross-cultural context is the 'Language' itself. Both teachers and learners face some limitations in different ways, dealing with language. The content of the language class can also be the issue of challenge. Last but not the least, culture shock is a severe obstacle in gaining desired goal. The most burning challenges are related to:

\section{Language}

\section{Native English speaking teachers}

Native speaker teachers' speed, accent, tone, pronunciation, pitch, can be sometimes a challenge for learners. They can not follow the instructor sometimes or even they don't understand anything. Some of the native English Speaking teachers' expectations of students is culturally based and stereotyped. Some western teachers may get frustrated over the perceived lack of imagination and creativity of their students without realizing the differences in uncertainty avoidance between cultures may be at the heart of this reluctance to stand out from the crowd (Scott A. Hipsher, 2006). On the other hand, it is also found that students have stereotype feeling for 
the instructor. In a study Luke Prodomou (1992) found that just over half of the students thought the native English speaking teacher should know the learners' mother tongue and know about local culture.

\section{Non-native speaker teacher}

Sometimes students think that non native English speaking teachers do not know much. In Bangladesh in United International University, one of my colleagues faced a question from a student, "Mam, Do you follow grammar, or does grammar follow you?" The student had little confidence on the non-native English teacher. On the other hand, Rampton (1990) asserts that linguistic 'expertise' is more important than notions of who is and who is not a 'native speaker'. In the long run, what seems to matter most to students is the teacher's ability to do the job; it is not 'who you are, but what you know' (Rampton, 1990:99 ) that students will pay for. Non-native-speaker teacher of English are not necessarily worse off than native -speaker colleagues: they can be, and often are, as 'expert' in English and ELT methodology as native speakers, and have the added advantage of being able to draw on the vast reservoir of the students' first language and culture (Atkinson, 1987).

\section{The learners}

They sometimes face language shock, that is, they experience doubt and possible confusion when using L2 (Schumann, 1978c). As English is not their mother tongue, they remain under pressure of accuracy, appropriacy and fluency. From my four years' teaching experience in a university in Bangladesh, I have often found students saying, "Sorry, mam. I can not explain in English. I don't find the right word at the right moment." Moreover, sometimes the structures are wrong, and there are too many pauses.

\section{Content}

Sometimes the content itself can be a problem for the learners. As they are being taught a different language, most often different cultures also come into play simultaneously. This may lead to some confusion, such as:

Guest(2002) has argued that attempts to identify national characteristics for the purpose of comparing and contrasting cultures, leads to oversimplification and stereotypes of cultural characteristics. This may lead to contradictions among the learners sometimes.

Frustration, anxiety and stress also occur whenever people can't find all the things they are accustomed to doing in their everyday lives. For example, sometimes because of differences in activities, norms, rituals, traditions, etc. that are found in the content of the lessons being taught in the English classroom, students from different background cannot cope with that successfully; ultimately, frustration, anxiety and stress arise. While practicing listening from New Headway Pre-Intermediate Student's Book in United International University in Bangladesh, most of the students feel awkward when they hear Mrs. Snell (T 1.4) talking openly about 'boys and girls living together and not married' as this is entirely against our norms and rituals.

In addition, if a person from a village comes to a busy big city or a person from a large continental urban society moves to a small island society, may experience a sense of social and spatial claustrophobia, more so than someone who is from a rural or small town society. It is true for the learners, and it can also be true for the teachers.

And lastly is the issue of values. A person can experience considerable stress and anxiety when they are living in a different culture with different values from their own. A person may find that some of their own cherished and deeply held values and assumptions about life may not be equally important to members of new culture. The areas of religion, moral behavior, justice and fair play, racial equality, work ethic and privacy are areas where there may be a great deal of cultural relativism, and people may find obscurity dealing with these differences. In Hollywood Kids [New Headway Pre-Intermediate Student's Book], 13 years old Trent has a credit card with students' great surprise.

\section{Culture shock}

Culture shock is the term used to denote the anxiety and stress reactions that some people experience when they live in a cultural and linguistic environment that is significantly different from 
their own (Schumann, 1978c). The anxiety, stress and resulting thoughts, emotions and behaviors are caused by cognitive dissonance and uncertainty due to disconfirmed expectancies and ego-identity diminishment. Cognitive dissonance (uneasiness) occurs when people's cognitions about themselves and the world around them are inconsistent with one another. The disconfirmed expectancies that we experience when living in a different culture contribute to this cognitive dissonance and to uncertainty, insecurity, anxiety and stress. In addition, individuals also experience anxiety and stress due to ego-identity diminishment. Our identities are rooted in our home culture and its particular physical and socio-cultural environment. When we leave that particular complex of socio-cultural and physical environmental factors we also leave the roots that support and nourish our personalities. Culture shock may arise in the following situations:

$\begin{array}{ll}\text { Ethnocentrism: } & \text { "My culture is the best." } \\ \text { Discrimination: } & \text { "I just cannot cope with } \\ & \text { the working class". }\end{array}$

Stereotyping: "She is an American. All Americans are libertines"

Cultural Blindness: "If I am a sensitive person I need not worry about other's culture".

Cultural Imposition: "We know what is best for you".

\section{Directions}

Tough every teacher has his or her own style of teaching, there are different national and cultural academic traditions, and there are often cultural differences in pedagogy. But regardless of styles, traditions and cultures, all good teaching anywhere in the world consists of one thing 'making connections'. It is important to bringing about knowledge and skills in students by making connections between the new things that we are trying to teach them and their existing information base and repertoire of skills. In a Piagetian perspective students build and expand upon schemas through accommodation and assimilation. And, from a Vygotskian point of view, students advance fully into their zone of proximal development through the assistance of parents, teachers and peers. Therefore, as teachers we have to ease the way of scaffolding for the students.

As we have identified three major areas regarding challenges, we will try to find out some solutions related to those broader aspects.

\section{Linguistic support}

Good teaching requires considerable linguistic supports. Teachers must utilize and build this supports into their courses, methods of classroom instruction and overall interaction with students whether they are native or non-native English speaking teachers.

\section{For teachers to remember}

We observed that students find difficulty in keeping with native speaking teachers. Therefore, linguistic supports should consist of an adjustment of the teacher's language which includes slowing down the pace at which the teacher explains material, simplifying his/ her English a little and keeping away from slang, jargon and idiomatic expressions, and in general controlling vocabulary and keeping to familiar words. In addition, for both native and non-native teachers, it is also helpful to either preview key vocabulary before a lecture or unit or else to stop and define words as one goes along. When the teacher is delivering lecture or explaining, it is a good practice to constantly repeat, to sum things up and then to repeat them again. And lastly it is important to ensure that the volume of the voice is loud enough for students to hear.

With respect to removing stereotypical language, the following strategies might be useful:

- Being aware of words, images and situations that suggest that all or most members of a racial group are the same

Example: "Why can't Joe ever be on time?" "He's African American, isn't he?"

- Avoiding using qualifiers that reinforce racial and ethnic stereotypes

Example: "The articulate African American student" implies that African American students typically have low verbal skills.

- Avoiding racial identification except when 


\section{it is essential to communication}

Example: "Judy, an outgoing student" is preferable to "Judy, an outgoing African American female student."

- Being aware of possible negative implications of color symbolism and usage that could offend people or reinforce bias

Example: Terms such as "black magic" or "black market" can be offensive.

- Avoiding language that has questionable racial or ethnic connotations

Example: Phrases such as "culturally deprived," "culturally disadvantaged" and "you people" have racist overtones.

\section{Teachers have to ensure the followings for students}

As we have noticed that the learners are under constant challenge in using English accurately, appropriately and fluently, we have to facilitate them with the following:

\section{Maximum exposure of English language}

Inside the classroom, maximum exposure of English language should be ensured. The medium of instruction will be English only. Using mother tongue should not be encouraged.

\section{Equipments used in the classroom}

Learning is greatly facilitated by using more audiovisual elements for teaching. Movies, multimedia slides, photographs, DVD and CD-ROMs are very effective.

\section{Focus on all skills}

Rather focusing on only writing, all the four skills along with grammar and vocabulary should be emphasized and evaluated. Then, students will feel importance of all skills.

\section{Ensuring more and more practice}

Inside the classroom, activities and tests, quizzes should be formulated and used in such a way that would initiate more and more practice of English language. Moreover, students can be motivated to use English outside the classroom also.

\section{Multi-cultural approach in content}

We can adopt multi-cultural approach in selecting content of the English course. A multi-cultural approach, particularly one which involves comparisons between students' culture and other cultures, is an important area to develop. A text in English by a write of a similar cultural background to the group of students studying the text may be more culturally accessible than a text written by an author from a culture far removed from the students' own. On the other hand, a text from another culture which deals with themes relevant to the students' own society may prove to be both accessible and absorbing. Through multicultural education, learners discover that all cultural groups have made significant contributions to civilization. A well balanced English course content can include literature that depicts people with a variety of aspirations, from different sociometric levels, with different occupations, and with a range of human characteristics (Norton, 1985). For overcoming cultural problems in content teachers can follow the following strategies (Gillian Lazar, 19930):

\section{Personalising}

We can cue students in to the theme or topic of the text by making it relevant to their own experience.

\section{Proving explanations/glosses}

We can provide a brief cultural information in a note or gloss.

Asking students to infer cultural information

Students can be encouraged to infer cultural information from a text by making the information explicit.

\section{Making cultural comparisons}

We can get the students to brainstorm ideas about their own society and then compare them with those in the text.

\section{Making associations}

We can enhance students' free associating around a word or phrase that might have particular connotations or even figurative meanings for a native speaker of the language.

\section{Eliminating culture shock}

We have already come to know that in cross cultural context differences exist in the communication 
styles of students and teachers. Perhaps the most important reason for educators to understand cross cultural communication is to improve their relations with the diverse groups of students. One way to improve relationships across cultural lines, particularly in the upper grades, is to develop a unit on "Communicating with One Another." The purpose of such a unit would be to teach students how to communicate more effectively across cultural lines and how to address and negotiate differences. It is also useful for teachers to brainstorm with one another on how to remove communication barriers. It can also be useful for teachers to identify sources of miscommunication and socially offensive behavior or language that can be shocking for students. Individuals are often keenly aware of how culture affects the behavior of those of another culture while not being aware of how their own behavior is also culturally oriented (Javidan \& House, 2001; Hofstede, 1983; McBurney and White; 2004).

- The attitudes which have been discussed earlier in challenge part that can cause culture shock should be avoided.

- Teachers should focus on students'

\section{Cognition:}

Cognitive supports consist of providing the students with adequate cognitive frameworks upon which the new information and skills can be attached in their minds. This includes the use of advance organizers such as outlines, models, concept maps and other graphic organizers whether they are in the form of handouts, overhead transparencies or just writing and drawing on the board. It also includes making things more concrete in the beginning and then moving toward the abstract and this is greatly facilitated by using more audiovisual elements for teaching. Movies, slides, textbook illustrations and photographs and CD-ROMs are very effective. In general, it is important to be sensitive to student cognitive processes. We must know our students' fields of experience, locate their experiences relevant to what we're teaching and then make the necessary connections through our teaching. From a strictly verbalperspective, there is nothing more important for effective teaching than a good example or good story that illustrates what it is we are trying to get our students to understand or serves as a heuristic that furthers their understanding. A picture is worth a thousand words and a good story can paint a picture in the minds of students. Some stories are quite universal and can be understood by students worldwide no matter what culture they are from, but other stories may need more cultural background for them to be effective.

\section{Motivation}

Motivational supports are also important, and we must build student success and self-esteem into our course structures and classroom methods. We need to be interesting and instill excitement about what we're teaching. We need to be relevant and connect to the reality of student lives and experiences. We need to demonstrate a purpose to learn besides just passing the course because it is a requirement. Gardner and Lambert (1972) define 'motivation' in terms of the L2 learner's overall goal or orientation. The motivated individual is goal-oriented, persistent, attentive and aroused. In fact, motivation plays a role in various ways in the process of learning a second language.

\section{Attitude}

Gardner and Lambert (1972) define 'attitude' as the persistence shown by the learner in striving for a goal.They have investigated a number of different attitudes which they consider relevant to L2 learning. Stern (1983:376-7) classifies these attitudes into three types: (1) attitudes towards the community and people who speak the L2, (2) attitudes towards learning the language concerned: and (3) attitudes towards languages and language learning in general. If the students have positive attitude towards the language, learning will be accelerated, so the teachers should also come forward to help the students having positive attitude.

\section{Low affective filter}

Krashen (1981a; 1982) incorporates the notion of the 'Affective filter' as proposed by Dulay and Burt (1977). The filter controls how much input the learner comes into contact with, and how much input is covered into intake. It is 'affective' because the factors which determine its strength have to do with the learner's motivation, self-confidence, or anxiety state. Learners with high motivation 
and self confidence and with low anxiety have low filters and so obtain and let in plenty of input. Learners with low motivation, little self confidence, and high anxiety have high filters and so receive little input and allow even less in. Therefore, the teaching and learning environment should promote low affective filter.

\section{Age}

Rate and success of SLA appear to be strongly influenced by the age of the learner. Where rate is concerned, there is evidence to suggest that older learners are better. Snow and Hoefnagel-Hohle (1978) have shown, the learners who progress most rapidly may be adolescents. Where success of SLA is concerned, the general finding is the longer the exposure to the L2, the more native-like L2 proficiency becomes. Therefore, the teachers should focus on maximum exposure of English language.

\section{Behaviour}

And then there are behavioral supports. We must structure our courses and classroom methods to provide maximum shaping and patterning of the requisite behaviors such as reading, writing, notetaking, studying, test-taking, asking questions, discussion and debate, and getting to class on time or getting to class at all. With regard to behavior modification, positive reinforcements (rewards) and negative reinforcements (removal of unpleasant stimuli) work better than punishments (giving unpleasantness).

\section{Teaching Method}

There are many methods, like, CLT, content based, task-based, teacher-oriented, student-centered, GT, etc. But the pathways to success in teaching English to the learners are rather challenging as there are no specific language teaching formula that always work with learners in all contexts. It is then the mission of an individual teacher to create and apply a multitude of teaching approaches, which will best suit their students.

\section{Conclusion}

Cross-cultural matters in language teaching is a symptom of wider social, politicaland technological developments, and there is no question that the successful integration of culture and language teaching can contribute significantly to general humanistic knowledge, that language ability and cultural sensitivity can play a vital role in the security, defense, and economic well-being of any country, and that global understanding ought to be a mandatory component of basic education. This urge was truly felt by Adrian Holliday, a keynote speaker in 16th NELTA International Conference (2011), where he posed some questions on what form of English to teach, the rules for correctness, multicultural and multilingual experience shared by students, and finally explored the opportunities of English in a multilingual and cross-cultural context. Abhi Subedi, in his plenary speech in the same conference, also focused on deconstruction of some taboos like English is only what is spoken and used in Britain and America, and emphasized on teaching English in multilingual and multicultural situations. At present, there is growing realization of the importance of culture within English teaching in Thailand also, and the need for teachers and learners to be aware of the complexity of culture. This was highlighted at the 2003 Thailand TESOL Conference entitled ELT 2003: Culture, Content, Competency in which a number of speakers (Damnet 2003, Wongbiasaj, 2003) discussed the importance of raising cultural awareness among Thai learners. In this article we demonstrated some promising challenges, but if we emerge towards the right direction, teaching English in a cross-cultural context can truly broaden the horizon of the learners. In short, we should not push students to learn, instead try to pull them into and support them within their learning zone of proximal development. Students will rise to our expectations if we provide them with a ladder to climb on. That ladder, or scaffold, consists of all the things we say and do in order to help students learn.

\section{The Author}

Sharmin Sultana is a Senior Lecturer in English at United International University. She did her M.A. in ELT and Applied Linguistics and B.A. (Hons.) in English from the University of Dhaka, Bangladesh. She presented papers in 16th International NELTA Conference (2011), in First EFL ESL Conference, organized by Asian EFL Journal and Rajasthan Bidyapeeth University, India (2009), in 3rd International conference, Bangladesh (2009). Another paper was published in ELT Weekly, India (2010). Her professional interests include ELT, linguistics, language, literature. 


\section{References}

Atkinson, D. (1987). The mother-tongue in the classroom: a neglected resource? ELT Journal, $41 / 4$.

Baker, W. (2003). Should culture be an overt component of EFL instruction outside English speaking countries? The Thai context. Asian EFL Journal.

Damnet, A. (2003) Acquisition of Intercultural Nonverbal Competence: Examining the Discourse, The $23^{\text {rd }}$ Thailand TESOL International Conference; January 23-25, 2003; Bangkok, Thailand.

Dulay, H. and M. Burt. (1977). Remarks on creativity in language acquisition. In M. Burt, H.Dulay, and M. Finocchiaro (eds.). Viewpoints on English as a Second Language. New York: regents.

Gardner, R.C., \& Lambert, W.E. (1972). Attitudes and motivation: Second language learning. Newbury House.

Griffith, D.A, Hu, M.Y. \& Ryans, J.K. Jr. (2000). Process standardization across intra- and intercultural relationships. Journal of International Business Studie, 31 (2) 303-324.

Guest, M. (2002) A critical 'checkbook' for culture teaching and learning, ELT Journal, 56/2: 154-161.

Hall, S. (Ed.). (1997). Introduction, representation: Cultural representations and signifying practices. (pp. 1-52).

Hipsher, Scott A. (2006) The Internet TESL Journal, Vol. XII, No. 3. http://iteslj.org/Articles/HipsherInternationalManagers.html

Holliday, A. (2011). English in a multilingual and cross-cultural context: Exploring opportunities and meeting the challenges. $16^{\text {th }}$ NELTA International Conference, February 18-20, 2011, Kathmandu, Nepal.

Javidan, M. \& House, R.J. (2001). Cultural acumen for the global manager: Lessons from Project Globe. Organizational Dynamics, 29 (4), 289-305.

Jiang, W. (1994). The relationship between culture and language. TESOL Quarterly, 28(3), 138-146.

Kienle, A.W. \& Loyd, N.L. (2005). Globalization and the emergence of supranational organizations: Implications for graduate programs in higher education administration. College Student Journal, 39 (3), 580-87.

Krashen, S. (1981a). Second Language Acquisition and Second Language Learning. Oxford: Pergamon.
Krashen, S. (1982). Principles and practice in Second Language Acquisition. Oxford: Pergamon.

Lazar, G. (1993). Reading literature crossculturally. Literature and Language Teaching. Cambridge University Press, 62-67.

Marx, K. and Engels (2004/1848). The Communist Manifesto. p.2; p 18. Marxist Internet Archive retrieved November 10, 2005 from www.marxist. org/http://www.marxists.org/archive/marx/ works/1848/communist-manifesto/index.htm.

Norton, D.E. (1985). Language and Cognitive Development Through Multicultural Literature. CHILDHOOD EDUCATION. 62, 2, 103-108.

Phillips, C.B. (1988). Nurturing Diversity For Today's Children and Tomorrow's Leaders. YOUNG CHILDREN. 43, 2, 42-47.

Prdomou, L. (1992). What culture? Which culture? Cross-cultural factors in language learning, $E L T$ Journal, 46/1: 39-50.

Rampton, M.B.H. (1990). Displacing the "native speaker": expertise, affiliation, and inheritance. ELT Journal, 44/2: 97-101.

Rivers, Wilga M. (1983). Communicating Naturally in a Second Language. Cambridge: Cambridge University Press.

Robinson, G.L.N. (1985). Crosscultural Understanding. Oxford: Pergamon.

Schumann, J. (1978c). The Acculturation model for second language acquisition. In R. Gingras (ed.). Second Language Acquisition and Foreign Language Teaching. Arlington, VA. Center for Applied Linguistics.

Snow, C. and M. Hoefnagel-Hohle. (1978). Age differences in second language acquisition. In Hatch (ed.) (1978a).

Subedi, A. (2011). English in Multilingual and Crosscultural Context: Exploring opportunities and meeting the challenges in English Teaching in Nepal. $16^{\text {th }}$ NELTA International Conference, February 18-20, 2011, Kathmandu, Nepal.

Timmis, I. (2002). Native speaker norms and International English: A classroom view, ELT Journal, 56/3:240-249.

Wongbiasaj, S. (2003) Cultural Competence Skills: A Learner Empowering Approach to Culture Learning, The $23^{\text {rd }}$ Thailand TESOL International Conference; January 23-25, 2003; Bangkok, Thailand. 